\title{
Noninfectious pulmonary complications of haematopoietic stem cell transplantation
}

\author{
Samran Haider, Navin Durairajan and Ayman 0. Soubani
}

Affiliation: Division of Pulmonary, Critical Care and Sleep Medicine, Wayne State University School of Medicine, Detroit, MI, USA.

Correspondence: Ayman 0. Soubani, Division of Pulmonary, Critical Care and Sleep Medicine, Wayne State University School of Medicine, 3990 John R- 3 Hudson, Detroit, MI 48201, USA. E-mail: asoubanidmed.wayne.edu

@ERSpublications

Noninfectious pulmonary complications following haematopoietic stem cell transplantation is a major cause of morbidity and mortality in this patient population. There are recent advances in the diagnosis and management of these conditions. http://bit.ly/2FgsIYG

Cite this article as: Haider S, Durairajan N, Soubani AO. Noninfectious pulmonary complications of haematopoietic stem cell transplantation. Eur Respir Rev 2020; 29: 190119 [https://doi.org/10.1183/ 16000617.0119-2019].

ABSTRACT Haematopoietic stem cell transplantation (HSCT) is an established treatment for a variety of malignant and nonmalignant conditions. Pulmonary complications, both infectious and noninfectious, are a major cause of morbidity and mortality in patients who undergo HSCT. Recent advances in prophylaxis and treatment of infectious complications has increased the significance of noninfectious pulmonary conditions. Acute lung injury associated with idiopathic pneumonia syndrome remains a major acute complication with high morbidity and mortality. On the other hand, bronchiolitis obliterans syndrome is the most challenging chronic pulmonary complication facing clinicians who are taking care of allogeneic HSCT recipients. Other noninfectious pulmonary complications following HSCT are less frequent. This review provides a clinical update of the incidence, risk factors, pathogenesis, clinical characteristics and management of the main noninfectious pulmonary complications following HSCT.

\section{Introduction}

Over 68000 haematopoietic stem cell transplantations (HSCTs) are carried out annually across 77 countries in the world and there has been a year to year increase in this life-saving treatment [1]. Done for a variety of benign and malignant diseases, stem cell transplantation can be grossly classified as autologous when the stem cells are obtained from the patient or allogeneic when taken from a donor. Expanding indications aside from acute leukaemia and aplastic anaemia (such as congenital disorders of the haematopoietic system, metabolic disorders, and autoimmune disease), extending donor availability (matched unrelated donors, partially matched related donors and umbilical cord-blood units), innovations in HSCT conditioning, better understanding of immunology, resulting in lower intensity conditioning regimens and development of new sources of stem cells have dramatically extended the availability of allogeneic transplantation [2,3], This has resulted in a decrease in transplant-related morbidity and mortality. Clinicians taking care of patients who have undergone HSCT must be aware of the type of transplantation, human leukocyte antigen (HLA) compatibility, conditioning regimen, graft-versus-host disease (GVHD), timing following transplantation and antimicrobial prophylaxis regimen as these important factors can affect the range of complications and outcomes [4].

Provenance: Submitted article, peer reviewed.

Received: 13 Sept 2019 | Accepted after revision: 11 Dec 2019

Copyright $\odot$ ERS 2020. This article is open access and distributed under the terms of the Creative Commons Attribution Non-Commercial Licence 4.0 . 
TABLE 1 Diagnostic criteria of idiopathic pneumonia syndrome following haematopoietic stem cell transplantation



Pulmonary complications are seen in up to one-third of patients undergoing HSCT and are associated with significant morbidity and mortality [5]. Factors associated with increased risk of pulmonary complications include older age, GVHD, conditioning regimen, stem cell source and underlying lung disease. Pre-transplant pulmonary function tests (PFTs), including forced expiratory volume in $1 \mathrm{~s}\left(\mathrm{FEV}_{1}\right)$ and diffusing capacity of the lung for carbon monoxide $\left(D_{\mathrm{LCO}}\right)$ are used for identifying patients at high risk of developing pulmonary complications, respiratory failure and/or mortality after HSCT [6-8]. Pre-transplant smoking history has also been shown to be an independent predictor of long-term complications and death [9-12].

Several advances in HSCT practice have decreased the overall incidence of these complications with improvement in mortality outcomes. The most significant change in practice is the ability to use a lower dose myeloablative regimen. This has also enabled older patients and those with comorbid conditions to receive a stem cell transplant [2]. Improved supportive care, including better strategies for pre-emptive detection and therapy of severe infectious complications and less toxic conditioning protocols have allowed for transplantation in older patients. Recipient age is rising and now HSCT is considered a treatment option in patients in their seventh decade $[1,13]$. The 100-day transplant-related mortality rates after allogeneic HSCT is $17-19 \%$ for noninfectious complications and $12-17 \%$ for infectious complications [13]. Antimicrobial prophylaxis and treatment strategies have effectively decreased the occurrence of infectious pulmonary complications after HSCT but the incidence of noninfectious lung injury continues to rise. In addition, improvement in supportive measures, including ventilatory strategies has resulted in better survival following acute noninfectious pulmonary complications and has augmented the significance of late noninfectious complications, such as bronchiolitis obliterans syndrome (BOS) and interstitial lung disease (ILD) $[2,5]$.

This review provides an overview of acute and chronic noninfectious pulmonary complications following HSCT, highlighting diagnostic criteria, incidence, pathogenesis, outcomes and recent advances in management.

\section{Idiopathic pneumonia syndrome}

The American Thoracic Society defines idiopathic pneumonia syndrome (IPS) as an idiopathic pneumopathy after HSCT. Diagnosis of IPS requires evidence of widespread alveolar injury (as evidenced by multilobular infiltration on imaging, signs and symptoms of pneumonia, increased A-a gradient or restrictive pattern on PFTs) in the absence of a concurrent infection, iatrogenic fluid overload, cardiac or renal dysfunction. (table 1). IPS occurs in both allogeneic and autologous HSCT patients. IPS is further classified based on the presumed site of tissue injury (table 2) [14]. Incidence of IPS following

TABLE 2 Clinical spectrum of idiopathic pneumonia syndrome following haematopoietic stem cell transplantation as categorised by presumed site of primary tissue injury

\begin{tabular}{|c|c|c|}
\hline Pulmonary parenchyma & Vascular endothelium & Airway epithelium \\
\hline Acute interstitial pneumonitis & $\begin{array}{l}\text { Peri-engraftment respiratory } \\
\text { distress syndrome }\end{array}$ & $\begin{array}{l}\text { Cryptogenic organising } \\
\text { pneumonia }\end{array}$ \\
\hline $\begin{array}{l}\text { Acute respiratory distress } \\
\text { syndrome }\end{array}$ & Diffuse alveolar haemorrhage & \\
\hline $\begin{array}{l}\text { Delayed pulmonary toxicity } \\
\text { syndrome }\end{array}$ & & \\
\hline
\end{tabular}


myeloablative preparative regimen is about $3-15 \%[15,16]$. Risk factors for IPS after allogeneic HSCT include full-intensity conditioning, total body irradiation, GVHD, age $>40$ years, underlying diagnosis of acute leukaemia or myelodysplastic syndrome $[14,15]$. Bronchoscopy with bronchoalveolar lavage (BAL) of effected areas is essential to exclude an infectious process [14].

The aetiology and pathogenesis of IPS are not clearly understood but it is believed to be secondary to cellular injury caused by a variety of lung insults, including toxic effects of HSCT conditioning regimens and immunologic cell-mediated injury [14].Tumour necrosis factor (TNF)- $\alpha$ released during this insult, is an important mediator of pulmonary injury in murine models [17]. Proinflammatory cytokines and TNF- $\alpha$ have been noted in BAL fluid of patients with IPS [18]. Use of etanercept and steroids has been explored for treatment in multiple clinical studies [17, 19-21].

The American Thoracic Society has proposed the term of "idiopathic pneumonia syndrome" to describe several clinical syndromes that are included under the umbrella of IPS and they generally reflect lung injury (table 2) [14].

\section{Peri-engraftment respiratory distress syndrome}

Peri-engraftment respiratory distress syndrome (PERDS) is a form of acute lung injury that occurs in a subset of patients with engraftment syndrome (ES), a diffuse systemic capillary leak disorder [22]. It is, in fact a part of both Spitzer and Maiolino diagnostic criteria for ES [23, 24]. PERDS is defined as hypoxaemic respiratory failure and bilateral pulmonary infiltrates that occur around the time of engraftment (within 3 days before and 7 days after neutrophil engraftment), not fully explained by cardiac dysfunction or infection [25]. Reported incidence rates vary widely in the literature (from $2.5 \%$ to $25 \%$ ) due in part to varying clinical defi, diagnostic criteria used and patient populations $[23,24,26-30]$.

Risk factors for developing PERDS include: female sex, rapid rate of immune system reconstitution, source of HSCT (peripheral blood versus bone marrow), intensity and choice of pre-treatment chemotherapy (less treatment was associated with increased risk) and use of granulocyte-macrophage colony-stimulating factor (GM-CSF) rather than granulocyte colony-stimulating factor (G-CSF) [22, 31-33]. PERDS is rare in allogeneic HSCT, but is more frequently reported following autologous HSCT [22, 27]. PERDS is increasingly observed after autologous HSCT and in certain indications for transplant (such as autoimmune diseases, POEMS and amyloidosis) where intensive chemotherapy before transplantation is not required $[34,35]$.

Although the exact mechanisms remain unclear, the role of activated granulocytes releasing proinflammatory cytokines (interleukin (IL)-1 $\beta$, IL-2, IL-6) and influx of neutrophils into the lungs during engraftment are postulated to play a primary role [36]. Other biomarkers such as serum procalcitonin, elafin and C-reactive protein (CRP) have also been noted to be increased indicating complex cytokine-mediated inflammation [36-38]. Given its timing around neutrophil recovery after HSCT, PERDS is considered a subtype of IPS. During the peri-engraftment period, more frequent use of GM-CSF causing rapid neutrophil recovery increases the risk of this syndrome [39-42]. GM-CSF causes dendritic cell activation and proliferation, and can cause capillary leak syndrome by itself [43]. Rapid engraftment after autologous HSCT may explain the higher incidence of PERDS in this population. In the allogeneic setting, it may be difficult to distinguish PERDS from acute GVHD, as there is significant overlap in clinical symptoms [22]. All these observations seem to indicate that less damaged stem cells, endothelial cells and tissues release more proinflammatory cytokines at the time of engraftment, facilitating the development of this syndrome [35].

The clinical manifestations and laboratory findings associated with PERDS are nonspecific and can overlap with differential diagnosis such as other forms of IPS, acute GVHD, drug toxicity, radiation-induced damage and infectious disorders, which are common in the early stages post-transplant. PERDS often presents along with ES, which has a distinct clinical presentation (noninfectious fever and rash) and better prognosis than other forms of IPS. Clinical clues to diagnosis include systemic inflammatory manifestations like diffuse skin rash, diarrhoea, hepatic dysfunction, renal dysfunction, transient encephalopathy and other capillary leak features, such as noncardiogenic pulmonary infiltrates, hypoxia and weight gain with no alternative etiologic basis other than engraftment. Radiologic features and symptoms can precede engraftment by up to a week [22]. PERDS in general, is typically self-limited. It however, responds to corticosteroids, like acute GVHD. Because ES and acute GVHD may have overlapping features and response to therapy, these disease processes may often not be distinct events [23]. If the fever does not respond to antibiotics, cultures are negative and there is a sudden increase in inflammatory markers such as CRP, there is enough evidence to establish the diagnosis of PERDS and to start the appropriate therapy [35].

The recommended management of PERDS includes the prompt treatment with a high dose of corticosteroids ( 1 to $2 \mathrm{mg} \cdot \mathrm{kg}^{-1}$ methylprednisolone twice daily for $3 \mathrm{~d}$ ), followed by a rapid taper [35, 36]. 
Response is typically rapid, with improvements in oxygenation in most patients within few days of initiation of treatment. Supportive measures include antipyretics, oxygen, diuretics and intubation/ mechanical ventilation.

Short term prognosis/mortality of ES and PERDS are generally good, especially after autologous HSCT, if recognised promptly and treatment is initiated early in the course [22]. Delayed recognition and treatment may lead to death in severe cases. There are no studies assessing short- and long-term outcomes for PERDS. However, patients with ES after allogeneic HSCT are noted to experience significantly higher cumulative incidence of grade 2-4 acute GVHD at day 100 (75\% versus 34\%) and higher nonrelapse mortality at 2 years (38\% versus 19\%) resulting in lower overall survival at 2 years (38\% versus $54 \%$, respectively, $\mathrm{p}<0.001$ ) compared with non-ES patients [44]. Future studies are required to better characterise the risk factors and underlying mechanisms in ES, detection of markers for early identification and treatment [22].

\section{Diffuse alveolar haemorrhage}

Diffuse alveolar haemorrhage (DAH) is a distinct subtype of IPS defined as BAL showing any of the following [45]: progressively bloodier return on serial lavages, $\geqslant 20 \%$ haemosiderin-laden macrophages or blood in at least $30 \%$ of alveolar surfaces [46]. It is characterised by rapid progression to respiratory failure [47]. DAH is considered more as a sign of underlying lung injury influenced by multiple risk factors than a distinct disease by itself [48]. Risk factors for DAH are multifactorial influenced by graft source (umbilical cord-blood source), higher dose/ myeloablative total body irradiation (TBI) regimen, increased age, delayed neutrophil/ platelet engraftment or primary graft failure [26, 47-48].

Since DAH commonly occurs within 2 weeks of neutrophil engraftment, this suggests that a sudden neutrophil influx (even during peri-engraftment period when patients are still neutropenic) may contribute to lung injury [36, 49-51]. Bronchial inflammation likely precedes alveolar inflammation [52, 53]. Damage to alveolar capillary endothelial membranes begins during preparative chemotherapy or TBI, resulting in release of inflammatory mediators [54]. In allogeneic transplants, donor T-cells react to host allo-antigens, become activated, proliferate and secrete inflammatory mediators, which may be amplified after endotoxin release from the gut after injury from mucositis or GVHD. In autologous HSCT recipients, the generation of cytokines is self-limited compared to allogeneic HSCT recipients and resolves in 7-10 days [55]. However, the frequency of DAH is similar between autologous and allogeneic groups which may be due to the protective effect of the immunosuppressive agents used for prophylaxis of GVHD in the allogeneic group. IL-12 levels at the time of leukocyte recovery, TNF- $\alpha$, and lipopolysaccharides have been associated with DAH in HSCT recipients [56,57]. The initial injury is compounded by damage related to the return of inflammatory cells to the lung, coincident with marrow recovery causing alveolitis and increasing in cell number/protein content of BAL [58]. G-CSF may also play a role by increasing neutrophil infiltration into the lungs [59].

Due to lack of large studies evaluating DAH in HSCT recipients, the exact pathogenesis of DAH in this population remains unclear. Most of the hypotheses are based on DAH in nontransplant patients, such as collagen vascular disorders where alveolitis due to immune-mediated mechanisms leads to damage to the alveolar microcirculation. But DAH is HSCT is multifactorial, beyond only immune-mediated injury, involving direct lung injury (from high-dose chemotherapy, chest radiation/TBI, undocumented infections, GVHD and toxicity from therapy for GVHD), vascular/endothelial injury including thrombotic microangiopathy and cytokine-mediated lung injury [59-62]. Animal models demonstrate role of donor T-lymphocytes in DAH post-HSCT [56]. Alterations in cardiopulmonary haemodynamics in the peri-transplantation period and infections that are common in the post-transplantation period are also potential contributors to the pathogenesis of this syndrome. Microorganisms (such as HHV-6, which are not regularly sought in the BAL fluid) could potentiate alveolar injury caused by chemotherapy, radiation therapy and GVHD; in addition to independently cause local inflammation and increase alveolar permeability [63].

DAH manifests as dyspnoea, nonproductive cough or haemoptysis and hypoxaemia with or without fever and may be progressive. Radiographically, diffuse alveolar and interstitial infiltrates in a predominantly central and basilar distribution are particularly suggestive of DAH; with a crazy-paving appearance [64] (figure 1). However, other patterns of diffuse opacities may also be seen [65]. In studies specifically examining DAH in transplant settings, the incidence ranges from $1 \%$ to $21 \%$ with similar rates between autologous and allogeneic HSCT. Median onset ranges from 11 to 21 days after HSCT [26, 50, 66]. Early flexible bronchoscopy in acute new pulmonary infiltrates in HSCT is associated with higher diagnostic yields and may favourably impact survival. DAH should be differentiated from infection-associated haemorrhage by the absence of any identifiable infection within 1 week of diagnosis of alveolar haemorrhage [63]. While, current literature on alveolar haemorrhage after HSCT has focused primarily on $\mathrm{DAH}$ and has excluded patients with underlying infections, there is possibly some overlap between DAH 
FIGURE 1 Chest computed tomography image of a patient with diffuse alveolar haemorrhage showing bilateral consolidative and groundglass changes.

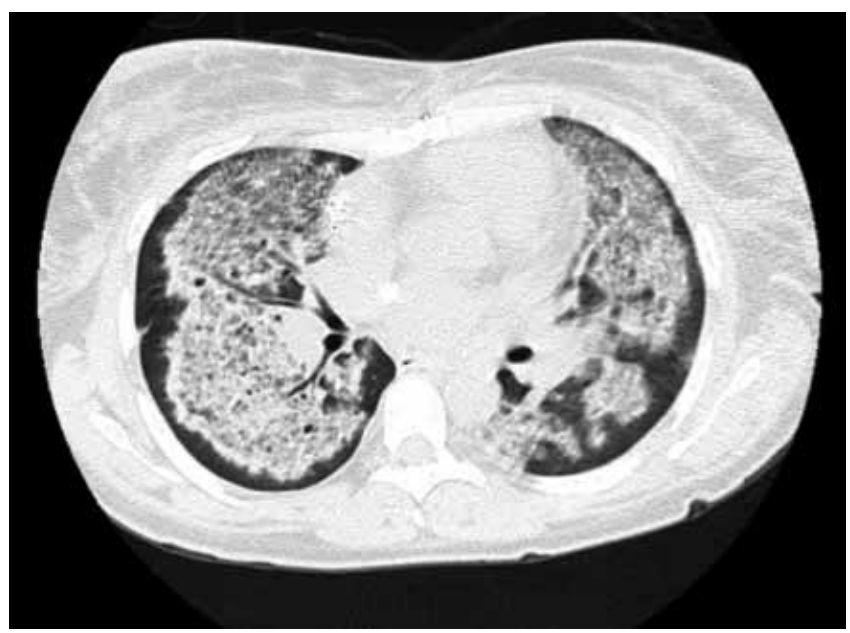

and infection-associated haemorrhage in clinical presentation, response to corticosteroids and overall outcome and makes the differentiation between the two challenging $[46,67,68]$.

Therapy remains empirical and thus inadequate, due in part to the unknown pathogenesis of the condition. Given the role of immune response and inflammation in pathogenesis of DAH, systemic corticosteroids are currently commonly used, with poor outcomes [69]. The exact dose of steroids $\left(<250 \mathrm{mg} \cdot \mathrm{day}^{-1}\right.$ for low, 250-1000 mg.day ${ }^{-1}$ for medium, $>1000 \mathrm{mg} \cdot \mathrm{day}^{-1}$ for high) continues to be a topic of debate since they show uniformly poor outcomes $[63,69]$. The overall high mortality ranges from $64 \%$ to $100 \%[53,58,60,70]$.

Supportive care may also include platelet transfusions [58, 63], procoagulant therapies (aminocaproic acid and recombinant factor VIIa) and cytokine antagonists (etanercept, cyclophosphamide), which have been used with variable success in small studies and are not routinely used as standard of care [64-70]. Although small studies have shown that recombinant factor VIIa was able to achieve local haemostasis, thus theoretically giving time to treat the underlying disease process, it does not resolve the underlying disease process and outcomes remain extremely poor in DAH patients after HSCT [71].

Mechanical ventilation is required in most cases. Extracorporeal membrane oxygenation (ECMO) has been used as a rescue therapy in the management of severe lung injury associated with DAH and other forms of IPS; however, it should be evaluated on an individual patient basis because of dismal survival rates [70-75]. The largest retrospective study involving patients receiving ECMO after allogeneic HSCT (37 patients) in Europe with severe lung injury showed discouraging survival rates of $4 \%$ in early post-allogeneic HSCT patients (ECMO initiated <240 days post-HSCT), but long-term allogeneic HSCT recipients (ECMO initiated $>240$ days post-HSCT) otherwise eligible for aggressive interventions may be potential candidates for ECMO as they showed a better survival rate (46\%) [76].

\section{Cryptogenic organising pneumonia}

Cryptogenic organising pneumonia (COP) previously called bronchiolitis obliterans organising pneumonia is a syndrome consisting of nonspecific respiratory symptoms (fever, dyspnoea, and cough), patchy consolidation on imaging and a restrictive ventilatory defect on pulmonary function testing [77]. COP has been reported after autologous as well as allogeneic HSCT but occurs more commonly in the latter with incidence ranging from 1-10\%, usually between 2 and 15 months after transplant [14, 78-80].

Risk factors based on retrospective studies include female-to-male HSCT, HLA incompatibility, acute or chronic GVHD and peripheral blood stem cell transplantation. Busulfan-based myeloablative conditioning, fludarabine-based reduced-intensity conditioning and in vivo T-cell ablation lower the risk. Symptoms of COP are nonspecific and include fever, dyspnoea and cough. It is commonly associated with GVHD of the skin (OR 1.65 with 95\% CI, 1.24-2.20 in one study) [78].

COP results from alveolar epithelial injury, causing an infiltration of inflammatory cells that later result in the formation of intra-alveolar buds of granulation tissue, consisting of intermixed myofibroblasts and connective tissue [81].

Pulmonary function testing shows a restrictive ventilatory defect, $\mathrm{FEV}_{1}$, forced vital capacity, total lung capacity, and $D_{\text {LCO }}$ are substantially reduced [79]. Computed tomography (CT) imaging commonly shows consolidation, which may be accompanied by ground-glass and nodular changes [82]. These radiological 
and physiological features differentiate COP from BOS. BAL should be strongly considered to exclude an infectious aetiology. BAL cytology shows hypercellularity with lymphocytosis $(>20 \%)$ and a decreased ratio of CD4/CD8 lymphocytes among patients with COP. A transbronchial lung biopsy when possible will provide confirmation of diagnosis [83].

$\mathrm{COP}$ is treated with a prolonged course of corticosteroids. There are varying reports of effective corticosteroid doses and duration of treatment reported in the literature. Patients are typically started on 0.5-1 $\mathrm{mg} \cdot \mathrm{kg}^{-1}$ prednisone dose with a slow taper. Relapses are common and may occur when the steroids are being tapered off $[84,85]$.

Delayed pulmonary toxicity syndrome (DPTS) is primarily seen in autologous stem cell transplant populations who received conditioning regimens containing bleomycin, bortezomib, thalidomide, cyclophosphamide, bischloroethyl nitrosourea, cisplatin and etoposide $[14,86]$. Median time of onset of DPTS is 45 days (range, 21-49 days) after HSCT. Reported incidence is between $29 \%$ and $64 \%$ in this population. Patients usually present with nonspecific symptoms including fever, dyspnoea, cough and hypoxaemia and have patchy or diffuse mixed reticular infiltrates on the chest radiograph. Lung biopsy shows diffuse alveolar damage, interstitial pneumonitis and early fibrosis. Treatment with high-dose steroids $\left(1 \mathrm{mg} \cdot \mathrm{kg}^{-1} \cdot \mathrm{d}^{-1}\right)$ leads to resolution in $>90 \%$ cases [14].

Patients exposed to pneumotoxic agents before autologous stem cell transplantation have significantly worse overall survival, event-free survival and infection-free interval [86]. Interstitial pneumonitis and idiopathic pulmonary fibrosis can be observed among patients treated with high-dose TBI [87]. Cyclosporine leads to two patterns of pneumonitis. Early-onset pneumonitis is reversible and may respond to corticosteroids, while late-onset has a chronically progressive course and does not respond well to corticosteroid therapy [88]. Fludarabine- and sirolimus-induced pulmonary toxicity are under recognised but respond to treatment with corticosteroids [89, 90]. Anti-thymocyte globulin has been reported to cause drug-induced noncardiogenic pulmonary oedema and acute respiratory distress syndrome [91].

\section{Bronchiolitis obliterans syndrome}

BOS is characterised by new-onset airflow limitation after allogeneic HSCT [92]. It is also reported among patients with certain inhalational exposure, rheumatoid arthritis and those who have undergone lung transplantation. Incidence has been reported to be $6.5 \%$ among patients who have undergone allogeneic HSCT [93]. Diagnosis of BOS has been associated with decreased health-related quality of life and survival $[94,95]$.

Histological analysis shows obliterative bronchiolitis with inflammation and fibrosis, leading to luminal narrowing and obliteration [92]. The diagnosis of BOS requires a surgical lung biopsy for confirmation which is rarely performed in this patient population. As a result, this entity is commonly referred to as BOS and is diagnosed based on spirometric and radiographic criteria.

Risk factors for development of BOS include: a busulfan-based (with or without combination with cyclophosphamide) conditioning regimen, ABO-mismatch HSCT, peripheral stem cell transplant, unrelated donors or female donors, viral respiratory tract infection (particularly parainfluenza, respiratory syncytial and human metanpneumovirus) diagnosed within the first 100 days, older age at transplant and poor baseline lung function. Anti-thymocyte globulin administration, receiving cord-blood transplantation and a reduced toxicity regimen are associated with a lower risk of developing BOS. Chronic GVHD, especially involving the skin and eye, are known to be associated with BOS [16, 19, 96-99].

Symptoms may include dyspnoea on exertion, cough or wheezing; however, many patients are asymptomatic early in the disease process. Diagnosis of BOS requires a PFT and expiratory CT thorax. Modified National Institutes of Health criteria published in 2014 are used and include: 1) $\mathrm{FEV}_{1} /$ vital capacity $<0.7$ or the 5 th percentile of predicted; 2 ) $\mathrm{FEV}_{1}<75 \%$ of predicted with $\geqslant 10 \%$ decline over less than 2 years $\left(\mathrm{FEV}_{1}\right.$ should not correct to $>75 \%$ of predicted with bronchodilators); 3 ) absence of respiratory tract infection; and 4) one of the two supporting features of BOS (evidence of air trapping by expiratory CT (mosaic pattern) (figure 2) or small-airway thickening or bronchiectasis by high-resolution chest CT) or evidence of air trapping by PFTs (RV (residual volume) $>120 \%$ of predicted or RV/total lung capacity elevated outside the $90 \%$ confidence interval (RV/total lung capacity) (table 3)). Restriction on PFT is not a recognised feature of BOS and should alert the clinician to an alternative diagnosis or possible concurrent extrathoracic process. Investigations are underway to identify biomarkers that may help in diagnosing BOS. Serum levels of B-cell-activating factor, $\mathrm{CD} 19^{+} \mathrm{CD} 21^{\text {low }} \mathrm{B}$-cells, hypoxia-inducible factor $1-\alpha($ HIF-1 $\alpha)$ have shown promise $[96,100]$.

Disease manifestations usually occur after 100 days and in the first 2 years of allogeneic HSCT. Clinical course is variable, with some patients showing a rapid decline in lung function, while others show a slowly 
FIGURE 2 High-resolution chest computed tomography image of a patient with bronchiolitis obliterans syndrome showing mosaic pattern.

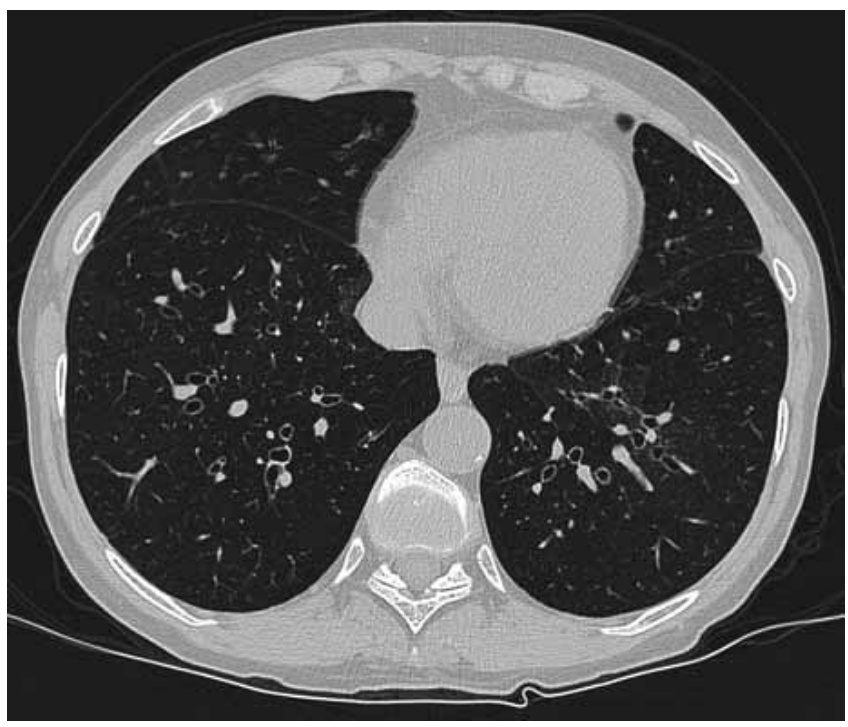

progressive disease with episodes of exacerbations [100, 101]. Rapid decliners are those who are diagnosed with BOS within 6 months of HSCT or show a 25\% decline in $\mathrm{FEV}_{1}$ within the first 3 months after BOS diagnosis. These patients have a shorter overall survival [94]. For this reason, screening PFTs are recommended at 100 days after transplant, at 1 year after transplant or at initial diagnosis of chronic GVHD. Continued screening with PFTs at 3-month intervals for the first 2 years after the initial diagnosis of chronic GVHD is also recommended [102, 103].

Historically, a prolonged course of corticosteroids and immunosuppressive therapy have been used to treat BOS. Extended corticosteroid courses are no longer recommended in these patients because it increases risk of side effects [104]. Treatment of BOS remains a challenge. Because of the rarity of the disease, there is a paucity of prospective clinical trials. Most treatment recommendations are based on retrospective studies and there are no consensus guidelines for therapy. In many situations, BOS following lung transplantation has provided guidance for the management of the disease following HSCT.

Observational retrospective studies have shown an improvement in clinical status as well as an increase in $\mathrm{FEV}_{1}$ among BOS patients treated with prolonged azithromycin [105, 106] A recently published meta-analysis of four studies comprising 90 allogeneic HSCT patients with BOS showed that azithromycin caused a mean increased in $\mathrm{FEV}_{1}$ by $30 \mathrm{~mL}$, but it is not known whether this results in clinical improvement [107]. Data from lung transplant patients are much more robust with randomised placebo-controlled trials showing deacceleration in the decline of $\mathrm{FEV}_{1}$, decrease in the incidence of BOS at 2 years among patients who were treated prophylactically with $250 \mathrm{mg}$ of azithromycin three times a week after lung transplant. Prolonged use of azithromycin was not associated with an increase in the rate of pneumonia nor colonisation of Pseudomonas sp. in this patient population [108].

TABLE 3 Diagnostic criteria of bronchiolitis obliterans syndrome following haematopoietic stem cell transplantation

$\mathrm{FEV}_{1} / \mathrm{FVC} \leqslant 0.7$

$\mathrm{FEV}_{1} \leqslant 75 \%$ of predicted with at least $10 \%$ decline from baseline, no significant post-bronchodilator response

Additional evidence of small-airway disease (at least 1 out of 3)

Evidence of air trapping, small-airway thickening or bronchiectasis on high-resolution computed tomography of chest (with inspiratory and expiratory cuts)

Residual volume $120 \%$, or elevated residual volume/total lung capacity

Pathologic confirmation of constrictive bronchiolitis

Absence of infection in the respiratory tract

By appropriate clinical, radiologic, microbiologic studies (sinus aspiration, upper respiratory tract, viral screen, sputum culture or bronchoalveolar lavage)

$\mathrm{FEV}_{1}$ : forced expiratory volume in $1 \mathrm{~s}$; FVC: forced vital capacity. 
Montelukast was recently studied in patients who developed BOS after lung transplantation and is also used in the management of this condition following allogeneic HSCT. Montelukast showed deacceleration in decline of $\mathrm{FEV}_{1}$ among patients with stage 1 BOS following lung transplantation when compared to placebo at 1 year (stage $1: \mathrm{FEV}_{1} 66-80 \%$ of baseline). Interestingly it decreased $\mathrm{FEV}_{1}$ in later stages (2-3) of BOS [109].

Inhaled budesonide/formoterol was studied in a multicentre, randomised, double-blind, placebo-controlled trial among 32 patients with BOS following allogeneic HSCT. The study showed an increase in $\mathrm{FEV}_{1}$ by a median of $240 \mathrm{~mL}$. Increase in $\mathrm{FEV}_{1}$ was sustained at the 6-month follow-up. Despite the improvement in $\mathrm{FEV}_{1}$, patients did not report an improvement in respiratory symptoms [110].

A prospective study was published of 36 patients with BOS who were treated with a combination therapy consisting of $440 \mu \mathrm{g}$ of inhaled fluticasone twice daily, $250 \mathrm{mg}$ of azithromycin orally every Monday, Wednesday, and Friday, and $10 \mathrm{mg}$ of montelukast orally every day for 6 months. The study reported a significant drop in corticosteroid dose, stabilisation of $\mathrm{FEV}_{1}$ and improved social functioning and emotional wellbeing scores at 3 months. The study was limited because of small number of patients, missing PFT data and limited follow-up among patients [111].

Given the frustrating treatment options for patients with BOS, studies are being considered for interventions that may prevent the development of this condition. Recently an important phase 3 trial (ALLOZITHRO) of $250 \mathrm{mg}$ of azithromycin three times per week compared to placebo during conditional regimen before allogeneic HSCT was published. Azithromycin did not prevent occurrence of BOS and increased haematological relapse (2-year cumulative incidence of $33.5 \%$ versus $22.3 \%$ in placebo) It was also reported to decrease "airflow decline-free survival" at 2 years $(32.8 \%$ versus $41.3 \%$; unadjusted hazard ratio of 1.3) [112]. It should be noted that this study was designed to prevent BOS rather than the management of patients with established BOS. The decision to stop or continue azithromycin in patients with established BOS should be decided on an individual basis. More studies are needed to determine the effect of azithromycin for the treatment of BOS.

Other treatments used in the management of BOS include extracorporeal photopheresis, tyrosine kinase inhibitors and rituximab, but studies on these modalities comprise a small number of patients [21, 113-115]. Lung transplantation may be the eventual treatment option [116]. One and 5-year survival for BOS patients following HSCT were similar to matched lung transplant controls ( $90 \%$ and $75 \%$ respectively) [117]. A recent retrospective matched case-control study comprising carefully selected lung transplantation candidates showed a $67 \%$ graft survival at 5 years among patients who developed BOS and other noninfectious pulmonary complications following allogeneic HSCT. Recurring malignancy was reported in only $4 \%$ patients. Sepsis accounted for $41 \%$ deaths in the cohort and lung transplantation within 2 years of HSCT was also associated with increased 1-year all-cause mortality [118].

There are two ongoing clinical trials exploring the use of inhaled cyclosporine and oral neutrophil elastase inhibitor for treatment of post-HSCT bronchiolitis obliterans (ClinicalTrials.gov identifiers: NCT01273207 and NCT02669251, respectively). Because small-airway fibrosis is involved in the pathogenesis of bronchiolitis obliterans, a number of clinical trials are exploring the role of antifibrotic medications used in the treatment of idiopathic pulmonary fibrosis. Randomised double-blinded placebo-controlled trials NCT02262299 and INFINITx-BOS are investigating the role of pirfenidone and nintedanib, respectively, among lung transplant patients who develop BOS. NINBOST 2018 is another clinical trial exploring the use of nintedanib among patients who develop BOS after HSCT.

Supportive measures are important in the management of BOS following HSCT. These include early identification and treatment of respiratory infections, treatment of gastro-oesophageal reflux disease and pulmonary rehabilitation $[103,119,120]$.

\section{Interstitial lung disease}

ILD is a rare chronic complication for HSCT. In a retrospective study of 1277 patients who underwent allogeneic HSCT, incidence was reported to be $2.4 \%$. Median time to diagnosis was 11.3 months. Most patients with ILD in this cohort had received peripheral stem cell transplantation (75\%) and had developed extrathoracic GVHD before diagnosis (70\%). Most patients on high-resolution computed tomography (HRCT) showed alveolar consolidation or ground-glass opacities. Restrictive ventilator defect was the predominant PFT pattern (83\%), although obstructive or mixed defect was also reported. BAL showed lymphocytic alveolitis with total lymphocyte count $>15 \%$ of total cells in $67 \%$ patients. Histological diagnosis was obtained in 7 of 10 patients and consisted of diffuse alveolar damage $(n=2)$, organising pneumonia $(n=2)$, nonspecific interstitial pneumonia $(n=2)$ and lymphocytic interstitial pneumonia $(n=1)$. Of note, four out of 10 patients experienced postoperative morbidity or mortality. Although no treatment guidelines are available, these patients were treated with corticosteroids and most 
showed improvement on imaging or PFTs. Overall prognosis of patients suffering from ILD after allogeneic HSCT is poor with a 39\% estimated mortality in 2 years [121]. Rarely, ILD may be associated with autoimmune diseases that develop as part of chronic GVHD. These include scleroderma, Sjogren, vasculitis, and mixed connective tissue disease [122].

Pleuroparenchymal fibroelastosis (PPFE) is another rare form of ILD following allogeneic HSCT. It is characterised by elastic fibre proliferation that leads pleural and subpleural parenchymal thickening. Inflammation is minimal [123]. PPFE may develop years after transplantation and its association with GVHD is inconsistent. A recent report of 15 cases mentioned that the median time of onset of PPFE was 8.9 years following allogeneic HSCT [124]. Chest CT usually shows upper lobe fibrosis with pleural and subpleural thickening with subpleural retraction, volume reduction and traction bronchiectasis. These changes later become diffuse. PPFE may also be associated with air leak syndrome [125]. Prognosis of PPFE is usually guarded with poor response to antifibrotic drugs reported in limited number of cases [126]. Lung transplantation is an option is highly selected patients [124, 127].

While BOS has been considered the only late manifestation of pulmonary GVHD, it is clear that lung involvement is more complex, with a range of conditions that include BOS, ILD and PPFE. Furthermore, there may be an overlap between these conditions in the same patient. This concept was recently demonstrated in a study of 60 patients who underwent lung transplant for chronic pulmonary complications following HSCT. In 29 of these patients there was extensive interstitial fibrosis, along with features of BOS on histological examination of explanted lungs. These observations are important to consider in the clinical evaluation of patients with pulmonary complications following HSCT and in future research [128].

\section{Pleural effusions}

Pleural effusions are also frequently encountered among patients with HSCT. In a large retrospective study of 618 patients who underwent allogeneic HSCT for haematological disorders, the incidence was reported to be $9.9 \%$ in the first year after HSCT. Patients developed this complication at a median of 40 days post-transplant. Pleural effusions in this cohort developed because of GVHD involving the pleura, GVHD drug regimen causing renal or hepatic injury, high volume fluid or multiple blood product transfusions and immunosuppression, resulting in pleural infections. Interestingly a higher rate of pleural effusions was noted among patients treated with mycophenolate-tacrolimus-thymoglobulin for GVHD prophylaxis. Early-onset ( $<100$ days) pleural effusion was commonly attributed to infections or volume overload. Other noninfectious causes in this group include sinusoidal obstruction syndrome, ES and malignant pleural effusion. Late-onset (>100 days) pleural effusions are also commonly due to volume overload or infections, but serositis-type GVHD involving the pleura may also be considered in differential diagnosis. Incidence of serositis-type GVHD is 0.8 to $1.23 \%$. Most patients develop extensive GVHD of other organs before development of serositis-type GVHD and may require repeated thoracentesis. Treatment involves increasing GVHD therapy after exclusion of other causes. Development of pleural effusion is associated with a decrease in overall survival regardless of the cause of the effusion [129].

FIGURE 3 Chest computed tomography image of a patient with pulmonary fibrosis and air leak syndrome.






\section{Thoracic air leak syndrome}

Thoracic air leak syndrome refers to the development of pneumomediastinum, spontaneous pneumothorax, subcutaneous emphysema and in rare cases pneumopericardium among allogeneic HSCT (figure 3) [121]. Thoracic air leak syndrome is a late complication and occurs among patients who develop $\mathrm{BO}, \mathrm{COP}$ and interstitial pneumonitis after stem cell transplant. It is a rare complication with reported incidence being $0.83 \%$ to $2.3 \%$ [130-132]. Risk factors include chronic GVHD, subsequent HSCT, male sex, age $<38$ years at transplant and tacrolimus-based GVHD prophylaxis [130].

Air leak syndrome results from the "Macklin effect", which starts with increased intra-alveolar pressure, resulting in alveolar rupture and increased intra-alveolar pressure that leads to alveolar rupture with air dissection along bronchovascular sheaths and spreading of pulmonary interstitial emphysema into the mediastinum [132].

Potential causes that increase intra-thoracic pressure (cough, vomiting) and underlying infectious causes (aspergillosis) must be evaluated. Large air leaks may be detected on chest radiographs; however, abnormalities may be subtle or absent. CT scan is much more sensitive and air within the pleural space, mediastinum, and subcutaneous tissue as well as interstitial emphysema appearing as linear lucencies along the bronchovascular bundles can be appreciated [133].

Thoracic air leak syndrome is associated with decreased survival, even with treatment (extraction of air, adjusting immunosuppressive medications) [130, 132]. Inpatient mortality is reported to be as high as $33 \%$ with $>90 \%$ 1-year mortality in one study [132].

\section{Venous thromboembolic disease}

Venous thromboembolic disease (VTE) encompasses upper and lower limb thromboembolism (including catheter-related VTE), pulmonary embolism or hepatic veno-occlusive disease. Incidence rates of all VTE range between $3-7 \%$, over a 1-4 year follow-up period [134, 135]. Traditional factors (such as age, sex, donor type or graft source) have not been proven to be a risk factor for VTE in the HSCT population [136]. However, other factors such as underlying malignancy (specifically lymphoma or multiple myeloma), high-dose myeloablative chemotherapy treatment, thrombocytopenia within 1 to 3 weeks after myeloablative therapy, total body radiation, prolonged hospital admissions leading to prolonged periods of immobility, previous VTE and presence of indwelling central venous catheters have been shown to be associated with increased VTE risk in this population [137-140]. Allogeneic HSCT might have a slightly higher risk of VTE (up to $8.3 \%$ over 4 years) than autologous HSCT [140]. This is likely due to the higher risk of GVHD, hepatic veno-occlusive disease in allogeneic HSCT (both of which are associated with vascular disruption and prolonged systemic inflammation). Smaller studies have shown that GVHD (45\% with acute and 35\% with chronic GVHD) significantly increases VTE risk [134, 139].

The increased risk of VTE in HSCT is probably related to thrombin generation, decreased antithrombin III levels, and endothelial cell damage $[41,141]$. The significant endothelial injury by the donor T-cells in acute GVHD, followed by inflammatory cascades and cytokine storm; and targeted epithelial damage, in addition to microvascular endothelial damage in chronic GVHD, contributes to increased risk of VTE [56, 142-144]. The complex haemostatic milieu of patients undergoing transplantation puts them at risk of VTE "despite" thrombocytopenia. Previous studies have shown $34 \%$ of VTE occur at platelet counts $<50 \times 109 \cdot \mathrm{L}^{-1}$; and $13 \%$ of VTE at platelet counts $<20 \times 109 \cdot \mathrm{L}^{-1}[135]$.

Most cases of VTE occur within 6-12 months of HSCT [138]. Among VTE, asymptomatic catheter-related thrombosis is the most common (19-41\%) and symptomatic thrombosis in only $1-4 \%$ of patients $[145,146]$. While lower extremity deep vein thrombosis and pulmonary embolism was associated with an increased risk of nonrelapse mortality (hazard ratio of 1.7), upper extremity or catheter-related thrombosis was not [140]. Despite the risk of VTE during the post-transplant period, VTE prophylaxis is not generally used in HSCT recipients [135]. Current practice of VTE prophylaxis varies significantly between institutions but utilisation rates of pharmacologic VTE prophylaxis are generally low (about 15\%) in both North America and internationally [145]. Carefully designed prospective interventional trials of thromboprophylaxis after HSCT are needed, targeting the subsets of patients that we have identified as being at the highest risk of VTE.

In patients with VTE, treatment should be decided on a case-by-case basis. Anticoagulation intensity is usually modified by decreasing the dose of anticoagulant in the setting of thrombocytopenia or other increased bleeding risks. Up to half of the HSCT recipients who receive treatment do not receive full-dose low-molecular-weight heparin due to thrombocytopenia, renal impairment and minor bleeding [146].

\section{Pulmonary hypertension}

Pulmonary hypertension $(\mathrm{PH})$ is an uncommon but potentially fatal complication of HSCT. It is haemodynamically defined as a mean pulmonary arterial pressure $>20 \mathrm{mmHg}$ and further classified into 
isolated pre-capillary $\mathrm{PH}$ (pulmonary artery wedge pressure $\leqslant 15 \mathrm{mmHg}$ and pulmonary vascular resistance $\geqslant 3 \mathrm{WU}$ ), isolated post-capillary $\mathrm{PH}$ (pulmonary artery wedge pressure $>15 \mathrm{mmHg}$ and pulmonary vascular resistance $\leqslant 3 \mathrm{WU}$ ) and combined pre- and post-capillary $\mathrm{PH}$ (pulmonary artery wedge pressure $\geqslant 15 \mathrm{mmHg}$ and pulmonary vascular resistance $\geqslant 3 \mathrm{WU}$ ) [147]. PH has mostly been reported in the paediatric HSCT population. Among 40 reported cases, the median age of diagnosis of $\mathrm{PH}$ after HSCT was 12.6 years with $70 \%$ patients having only pulmonary arteriole involvement and $23 \%$ patients reporting pulmonary veno-occlusive disease (PVOD). In such patients, up to $86 \%$ mortality was attributed to $\mathrm{PH}$. It occurs among patients receiving myeloablative as well as reduced-intensity regimens. It is likely that PH is undiagnosed among the HSCT population because of its vague clinical presentation [148]. Pathogenesis, incidence, aetiology and risk factors among the adult HSCT population remains unknown due to paucity of data; however, it should be considered in the differential diagnosis among patients with unexplained hypoxia or dyspnoea.

PVOD is a rare variant of $\mathrm{PH}$ and has been reported among both paediatric and adult patients with HSCT. Pulmonary vascular endothelial damage from cytotoxic medications and radiation therapy has been postulated as a cause of PVOD. Among the reported cases, patients responded to vasodilators as well as steroids; however, the role of these agents remain poorly understood [149]. A retrospective analysis of 386 adult lung transplant recipients with BOS from all causes who were relisted for transplantation showed a prevalence of $\mathrm{PH}$ in 32.5\% patients [150]. Given the high prevalence in the post-transplant population, some experts have started screening patients with BOS after HSCT for PH using transthoracic echocardiography [151].

\section{Post-transplant lymphoproliferative disorder}

Post-transplant lymphoproliferative disorder (PTLD) is a rare complication after allo-HSCT and comprises a spectrum of lymphoid proliferation in the setting of immunosuppression that follows both solid organ or HSCT [152]. Histologically, it includes reactive plasmocytic hyperplasia, polymorphic PTLD, monomorphic lymphoma of B-cell or rarely, T-cell lineage or Hodgkin lymphoma, which is the least common of the four classes [153]. PTLD is essentially a donor-cell-derived lymphoma that is more common after allogeneic HSCT with T-cell depletion or an intensive immune-suppression state. PTLD after autologous HSCT is extremely rare [154].

PTLD is caused by opportunistic expansion of Epstein-Barr virus (EBV)-transformed B-lymphocytes in the T-cell-compromised host. The reported incidence following HSCT ranges from 0.2 to $11 \%$ [155]. Risk factors include T-cell depletion of the donor marrow, use of anti-thymocyte globulin, unrelated or HLA-mismatched grafts, presence of acute or chronic GVHD, older age at HSCT, and multiple transplants $[155,156]$. Because immune reconstitution after transplant can usually take up to 6 months, it is understandable that PTLD is highest in the first 6 months following transplantation (median 2-4 months), with $70 \%$ of cases reported during that time frame [157]. Only $4 \%$ of cases develop later than 12 months after HSCT [158].

PTLD can occur in almost any organ/tissues but intra-thoracic involvement is most commonly encountered. Fever, lymphadenopathy and respiratory complaints are the most common symptoms of pulmonary PTLD [152]. Among intra-thoracic PTLD, lymphadenopathy is more common than parenchymal lung involvement and the lesions showed hypermetabolism on fluorodeoxyglucose positron emission tomography [159]. Pulmonary parenchymal involvement in PTLD usually manifests as nodules or masses (single or multiple), alveolar infiltrates or a combination of these. Extraparenchymal disease may also manifest as pleural effusion and rarely as interstitial pneumonia [160-163]. Differential diagnosis includes EBV-associated pneumonia. BAL fluid cytology and EBV along with histopathologic characteristics of a surgical lung biopsy help in differentiating these two conditions [164, 165]. A high index of suspicion together with clinical, radiological and EBV viral load data is required to improve diagnostic sensitivity and specificity. The diagnostic approach to PTLD should, preferably, be based on biopsies of enlarged lymph nodes and other sites of suspected EBV disease. However, this is often impossible due to the clinical status of the patient. Hence, noninvasive approaches using quantitative EBV DNA titres combined with positron emission tomography-CT/CT imaging can be considered [166].

Treatment options include reduction of immunosuppression alone as pre-emptive therapy, administration of rituximab or a combination of both [167-170]. If not treated, it is associated with rapidly progressive multiorgan failure and death [171].

\section{Diagnostic considerations of noninfectious pulmonary complications following HSCT}

It is important for the management of post-HSCT pulmonary complications that all these patients are evaluated pre-transplant by thorough history, physical examination, PFT and chest radiography. Chest CT 
scans may be indicated, especially in older patients, smokers or those that have an abnormal initial evaluation. These investigations should serve as a baseline for any post-transplant changes.

Respiratory symptoms in the early post-transplant period (generally in the first 100 days following transplant) should be evaluated in the context of acuity of symptoms, patient's immune status (neutrophil count, immunosuppressive medications, presence of acute GVHD and antimicrobial prophylactic measures). Infectious conditions should be considered first during this period. HRCT of the chest is more sensitive in detecting pulmonary opacities and may provide useful information on the aetiology of the patient's symptoms [172]. Bronchoscopy with BAL is well tolerated and provides a diagnosis in around half of the patients [173]. Recent advances in noninvasive diagnostic methods have reduced the need for bronchoscopy in this patient population [174]. These include viral PCR studies of nasal washing and serological tests, such as galactomannan and cytomegalovirus PCR [175]. Surgical lung biopsies are rarely needed nowadays following HSCT and the decision to proceed with this procedure should be made in a multidisciplinary approach and on a case-by-case basis [176].

In the late post-HSCT period, chronic noninfectious pulmonary complications, including BOS, ILD or mixed changes gain more significance. Given the limited treatment options once the damage associated with these conditions has been established, it is recommended to monitor patients carefully following HSCT by regular outpatient visits and review of the patient's respiratory symptoms. Screening spirometry every 3 months after the initial 100 days and for the first 2 years following allogeneic HSCT is recommended by the National Institutes of Health 2014 Consensus conference on chronic GVHD and Consensus Conference on Clinical Practice in chronic GVHD [103, 104, 177]. The presence of a new obstructive pattern compared to baseline values is consistent with BOS, whereas a new restrictive finding is suggestive of ILD. Occasionally, patients may have combined new obstructive and restrictive changes that reflect a mixed pattern of BOS and ILD. If there are persistent new changes on PFT, HRCT is helpful in

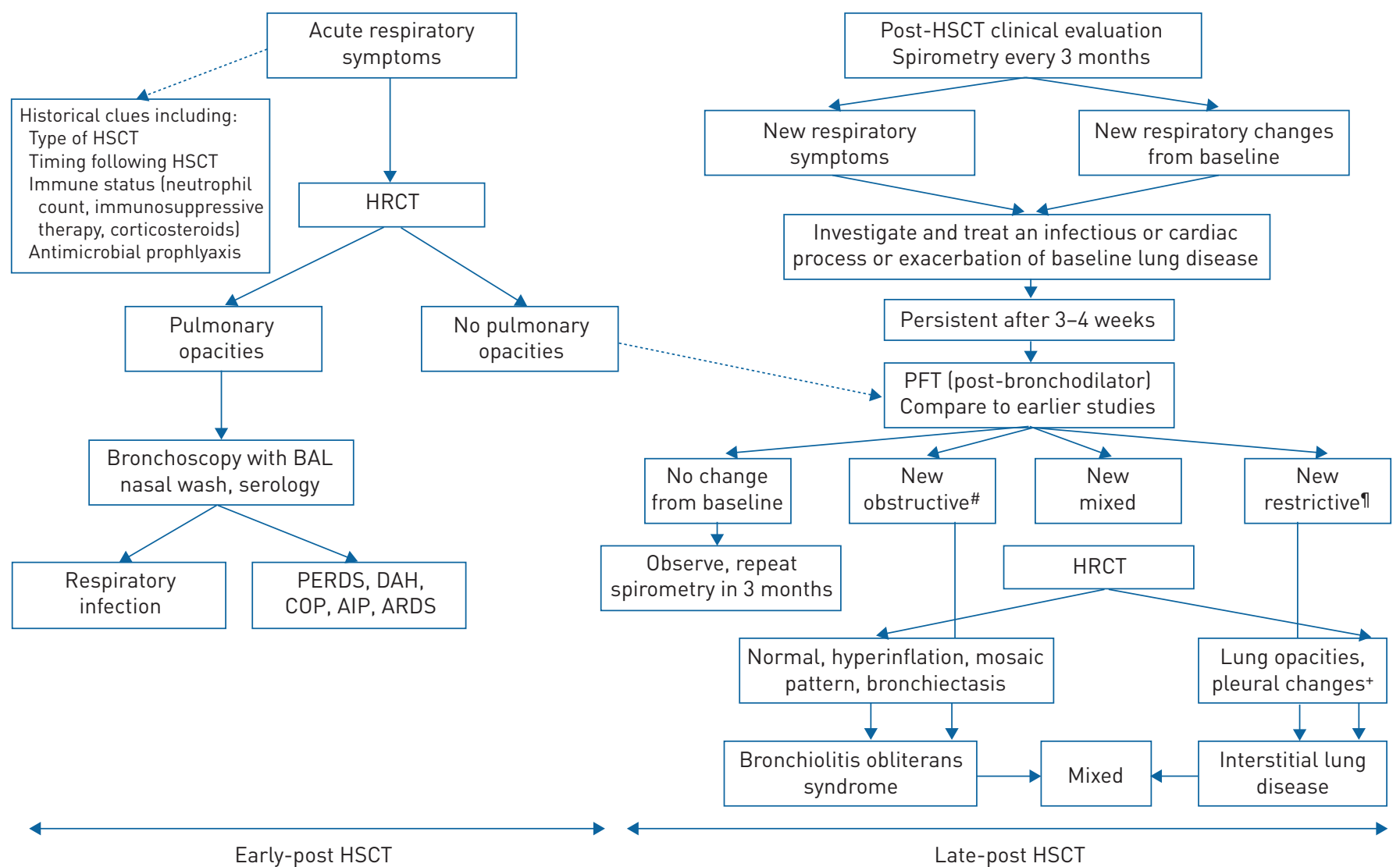

FIGURE 4 Algorithm of the initial diagnostic approach to haematopoietic stem cell transplantation (HSCT) patients presenting with new respiratory symptoms. HRCT: high-resolution computed tomography; BAL: bronchoalveolar lavage; PERDS: peri-engraftment respiratory distress syndrome; DAH: diffuse alveolar haemorrhage; COP: cryptogenic organising pneumonia; AIP: acute interstitial pneumonitis; ARDS: acute respiratory distress syndrome; PFT: pulmonary function test. \#: spirometry showing forced expiratory volume/forced vital capacity $<0.7$ and decrease in forced expiratory volume in $1 \mathrm{~s} \geqslant 10 \%$ from baseline. ${ }^{\Uparrow}$ : decline in total lung capacity $\geqslant 10 \%$ from baseline. ${ }^{+}$: persistent multilobar opacities (ground-glass, consolidation, small linear and reticular) with increasing pleural thickening consistent with pulmonary and/or pleural fibrosis. 
delineating the pulmonary disease. The findings of nonhomogeneous air trapping by expiratory CT (mosaic pattern), small-airway thickening or bronchiectasis are consistent with BOS, whereas ILD associated with GVHD usually manifests radiologically with persistent multilobar opacities (ground-glass, consolidation, small linear and reticular changes) with or without pleural changes [178].

An approach to the evaluation of noninfectious pulmonary complications following HSCT is summarised in figure 4 .

\section{Conclusion}

Non-infectious pulmonary complications are gaining more significance among patients post-HSCT. Diagnostic criteria and terminology for these disorders remain confusing due to significant overlap among the clinical entities described above and their coexistence with infectious complications. With an increase in the number of HSCTs performed, knowledge of pulmonary complications after HSCT is becoming increasingly important. Unfortunately, well-designed clinical trials for the management of these conditions are lacking. Multicentre collaboration to collect data on risk factors, diagnostic approaches and management strategies is necessary.

Conflict of interest: None declared.

\section{References}

1 Niederwieser D, Baldomero H, Szer J, et al. Hematopoietic stem cell transplantation activity worldwide in 2012 and a SWOT analysis of the Worldwide Network for Blood and Marrow Transplantation Group including the global survey. Bone Marrow Transplant 2016; 51: 778-785.

2 Gooley TA, Chien JW, Pergam SA, et al. Reduced mortality after allogeneic hematopoietic-cell transplantation. N Engl J Med 2010; 363: 2091-2101.

3 Kassim AA, Savani BN. Hematopoietic stem cell transplantation for acute myeloid leukemia: a review. Hematol Oncol Stem Cell Ther 2017; 10: 245-251.

4 Sahin U, Toprak SK, Atilla PA, et al. An overview of infectious complications after allogeneic hematopoietic stem cell transplantation. J Infect Chemother 2016; 22: 505-514.

5 Chi AK, Soubani AO, White AC, et al. An update on pulmonary complications of hematopoietic stem cell transplantation. Chest 2013; 144: 1913-1922.

6 Cheng GS. Pulmonary function and pretransplant evaluation of the hematopoietic cell transplant candidate. Clin Chest Med 2017; 38: 307-316.

7 Wasilewska E, Kuziemski K, Niedoszytko M, et al. Impairment of lung diffusion capacity-a new consequence in the long-term childhood leukaemia survivors. Ann Hematol 2019; 98: 2103-2110.

8 Chien JW, Madtes DK, Clark JG. Pulmonary function testing prior to hematopoietic stem cell transplantation. Bone Marrow Transplant 2005; 35: 429-435.

9 Scheidl S, Zinke-Cerwenka W, Flick $\mathrm{H}$, et al. Whole-body lung function test-derived outcome predictors in allogenic stem cell transplantation. Biol Blood Marrow Transplant 2019; 25: 129-136.

10 Varadarajan R, Licht AS, Hyland AJ, et al. Smoking adversely affects survival in acute myeloid leukemia patients. Int J Cancer 2012; 130: 1451-1458.

11 Ehlers SL, Gastineau DA, Patten CA, et al. The impact of smoking on outcomes among patients undergoing hematopoietic sct for the treatment of acute leukemia. Bone Marrow Transplant 2011; 46: 285-290.

12 Chang G, Orav EJ, McNamara T, et al. Depression, cigarette smoking and hematopoietic stem cell transplantation outcome. Cancer 2004; 101: 782-789.

13 Henig I, Zuckerman T. Hematopoietic stem cell transplantation-50 years of evolution and future perspectives. Rambam Maimonides Med J 2014; 5: e0028.

14 Panoskaltsis-Mortari A, Griese M, Madtes DK, et al. An official American Thoracic Society research statement: noninfectious lung injury after hematopoietic stem cell transplantation: idiopathic pneumonia syndrome. Am J Respir Crit Care Med 2011; 183: 1262-1279.

15 Fukuda T, Hackman RC, Guthrie KA, et al. Risks and outcomes of idiopathic pneumonia syndrome after nonmyeloablative and conventional conditioning regimens for allogeneic hematopoietic stem cell transplantation. Blood 2003; 102: 2777-2785.

16 Cengiz Seval G, Topçuoğlu P, Demirer T. Current approach to non-infectious pulmonary complications of hematopoietic stem cell transplantation. Balkan Med J 2018; 35: 131-140.

17 Thompson J, Yin Z, D'Souza A, et al. Etanercept and corticosteroid therapy for the treatment of late-onset idiopathic pneumonia syndrome. Biol Blood Marrow Transplant 2017; 23: 1955-1960.

18 Clark JG, Madtes DK, Martin TR, et al. Idiopathic pneumonia after bone marrow transplantation: cytokine activation and lipopolysaccharide amplification in the bronchoalveolar compartment. Crit Care Med 1999; 27: 1800-1806.

19 Yanik GA, Ho VT, Levine JE, et al. The impact of soluble tumor necrosis factor receptor etanercept on the treatment of idiopathic pneumonia syndrome after allogeneic hematopoietic stem cell transplantation. Blood 2008; 112: 3073-3081.

20 Tizon R, Frey N, Heitjan DF, et al. High-dose corticosteroids with or without etanercept for the treatment of idiopathic pneumonia syndrome after allo-SCT. Bone Marrow Transplant 2012; 47: 1332-1337.

21 Brownback KR, Thomas LA, McGuirk JP, et al. Effect of rituximab on pulmonary function in bronchiolitis obliterans syndrome due to graft-versus-host-disease. Lung 2017; 195: 781-788.

22 Cornell RF, Hari P, Drobyski WR. Engraftment syndrome after autologous stem cell transplantation: an update unifying the definition and management approach. Biol Blood Marrow Transplant 2015; 21: 2061-2068. 
Spitzer TR. Engraftment syndrome: double-edged sword of hematopoietic cell transplants. Bone Marrow Transplant 2015; 50: 469-475.

Maiolino A, Biasoli I, Lima J, et al. Engraftment syndrome following autologous hematopoietic stem cell transplantation: definition of diagnostic criteria. Bone Marrow Transplant 2003; 31: 393-397.

Wieruszewski PM, Herasevich S, Gajic O, et al. Respiratory failure in the hematopoietic stem cell transplant recipient. World J Crit Care Med 2018; 7: 62-72.

Afessa B, Abdulai RM, Kremers WK, et al. Risk factors and outcome of pulmonary complications after autologous hematopoietic stem cell transplant. Chest 2012; 141: 442-450.

Gorak E, Geller N, Srinivasan R, et al. Engraftment syndrome after nonmyeloablative allogeneic hematopoietic stem cell transplantation: incidence and effects on survival. Biol Blood Marrow Transplant 2005; 11: 542-550.

Schmid I, Stachel D, Pagel P, et al. Incidence, predisposing factors and outcome of engraftment syndrome in pediatric allogeneic stem cell transplant recipients. Biol Blood Marrow Transplant 2008; 14: 438-444.

Al-Anazi KA. Autologous hematopoietic stem cell transplantation for multiple myeloma without cryopreservation. Bone Marrow Res 2012; 2012: 917361.

Sheth V, Jain R, Gore A, et al. Engraftment syndrome: clinical features and predictive factors in autologous stem cell transplant. Indian J Hematol Blood Transfus 2018; 34: 448-453.

Martínez-Cibrian N, Magnano L, Gutiérrez-García G, et al. At-home autologous stem cell transplantation in multiple myeloma with and without G-CSF administration: a comparative study. Bone Marrow Transplant 2016; 51: 593-595.

Akasheh M, Eastwood D, Vesole DH. Engraftment syndrome after autologous hematopoietic stem cell transplan supported by granulocyte-colony-stimulating factor (G-CSF) versus granulocyte-macrophage colony-stimulating factor (GM-CSF). Bone Marrow Transplant 2003; 31: 113-116.

Gutiérrez-García G, Rovira M, Magnano L, et al. Innovative strategies minimize engraftment syndrome in multiple myeloma patients with novel induction therapy following autologous hematopoietic stem cell transplantation. Bone Marrow Transplant 2018; 53: 1541-1547.

Dispenzieri A, Lacy MQ, Hayman SR, et al. Peripheral blood stem cell transplant for POEMS syndrome is associated with high rates of engraftment syndrome. Eur J Haematol 2008; 80: 397-406.

Carreras E, Fernández-Avilés F, Silva L, et al. Engraftment syndrome after auto-SCT: analysis of diagnostic criteria and risk factors in a large series from a single center. Bone Marrow Transplant 2010; 45: 1417-1422.

Capizzi SA, Kumar S, Huneke NE, et al. Peri-engraftment respiratory distress syndrome during autologous hematopoietic stem cell transplantation. Bone Marrow Transplant 2001; 27: 1299-1303.

Khandelwal P, Mellor-Heineke S, Rehman N, et al. Cytokine profile of engraftment syndrome in pediatric hematopoietic stem cell transplant recipients. Biol Blood Marrow Transplant 2016; 22: 690-697.

Shah NN, Watson TM, Yates B, et al. Procalcitonin and cytokine profiles in engraftment syndrome in pediatric stem cell transplantation. Pediatr Blood Cancer 2017; 64.

Rabinowitz JD, Petros WP, Stuart AR, et al. Characterization of endogenous cytokine concentrations after high-dose chemotherapy with autologous bone marrow support. Blood 1993; 81: 2452-2459.

Young JW, Steinman RM. The hematopoietic development of dendritic cells: a distinct pathway for myeloid differentiation. Stem Cells 1996; 14: 376-387.

Chasty RC, Lamb WR, Gallati $\mathrm{H}$, et al. Serum cytokine levels in patients undergoing bone marrow transplantation. Bone Marrow Transplant 1993; 12: 331-336.

Holler E, Kolb HJ, Möller A, et al. Increased serum levels of tumor necrosis factor- $\alpha$ precede major complications of bone marrow transplantation. Blood 1990; 75: 1011-1016.

Nürnberger W, Willers R, Burdach S, et al. Risk factors for capillary leakage syndrome after bone marrow transplantation. Ann Hematol 1997; 74: 221-224.

Chang L, Frame D, Braun T, et al. Engraftment Syndrome after allogeneic hematopoietic cell transplantation predicts poor outcomes. Biol Blood Marrow Transplant 2014; 20: 1407-1417.

De Lassence A, Fleury-Feith J, Escudier E, et al. Alveolar hemorrhage. diagnostic criteria and results in 194 immunocompromised hosts. Am J Respir Crit Care Med 1995; 151: 157-163.

Agustí C, Ramirez J, Picado C, et al. Diffuse alveolar hemorrhage in allogeneic bone marrow transplantation. A postmortem study. Am J Respir Crit Care Med 1995; 151: 1006-1010.

Ahya VN. Noninfectious acute lung injury syndromes early after hematopoietic stem cell transplantation. Clin Chest Med 2017; 38: 595-606.

Keklik F, Alrawi EB, Cao Q, et al. Diffuse alveolar hemorrhage is most often fatal and is affected by graft source, conditioning regiment toxicity and engraftment kinetics. Haematologica 2018; 103: 2109-2115.

Chan CK, Hyland RH, Hutcheon MA. Pulmonary complications following bone marrow transplantation. Clin Chest Med 1990; 11: 323-332.

Robbins RA, Linder J, Stahl MG, et al. Diffuse alveolar hemorrhage in autologous bone marrow transplant recipients. Am J Med 1989; 87: 511-518.

Weisdorf DJ. Diffuse alveolar hemorrhage: an evolving problem? Leukemia 2003; 17: 1049-1050. bone marrow transplantation in patients with Hodgkin disease. Am Rev Respir Dis 1992; 146: 439-443.

Vaughan WP, Linder J, Robbins R, et al. Pulmonary surveillance using bronchoscopy and bronchoalveolar lavage during high-dose antineoplastic therapy. Chest 1991; 99: 105-111.

Haselton DJ, Klekamp JG, Christman BW, et al. Use of high-dose corticosteroids and high-frequency oscillatory ventilation for treatment of a child with diffuse alveolar hemorrhage after bone marrow transplantation: case report and review of the literature. Crit Care Med 2000; 28: 245-248.

Ferrara JL. Cytokines other than growth factors in bone marrow transplantation. Curr Opin Oncol 1994; 6: 127-134.

Piguet PF, Grau GE, Collart MA, et al. Pneumopathies of the graft-versus-host reaction. alveolitis associated with an increased level of tumor necrosis factor mrna and chronic interstitial pneumonitis. Lab Invest 1989; 61: $37-45$.

57 Cooke KR. Acute lung injury after allogeneic stem cell transplantation: from the clinic, to the bench and back again. Pediatr Transplant 2005; 9: Suppl. 7, 25-36. 

associated with bone marrow transplantation. University of Nebraska Medical Center Bone Marrow Transplant Group. Am J Med 1994; 96: 327-334.

59 Meng ZH, Dyer K, Billiar TR, et al. Distinct effects of systemic infusion of G-CSF vs. IL-6 on lung and liver inflammation and injury in hemorrhagic shock. Shock 2000; 14: 41-48.

60 Wojno KJ, Vogelsang GB, Beschorner WE, et al. Pulmonary hemorrhage as a cause of death in allogeneic bone marrow recipients with severe acute graft-versus-host disease. Transplantation 1994; 57: 88-92.

61 Srivastava A, Gottlieb D, Bradstock KF. Diffuse alveolar haemorrhage associated with microangiopathy after allogeneic bone marrow transplantation. Bone Marrow Transplant 1995; 15: 863-867.

62 Jillella AP, Ustun C. What is the optimum number of $\mathrm{CD} 34^{+}$peripheral blood stem cells for an autologous transplant? Stem Cells Dev 2004; 13: 598-606.

63 Majhail NS, Parks K, Defor TE, et al. Diffuse alveolar hemorrhage and infection-associated alveolar hemorrhage following hematopoietic stem cell transplantation: related and high-risk clinical syndromes. Biol Blood Marrow Transplant 2006; 12: 1038-1046.

64 Tanaka N, Kunihiro Y, Kobayashi T, et al. High-resolution CT findings of idiopathic pneumonia syndrome after haematopoietic stem cell transplantation: based on the updated concept of idiopathic pneumonia syndrome by the American Thoracic Society in 2011. Clin Radiol 2016; 71: 953-959.

65 Witte RJ, Gurney JW, Robbins RA, et al. Diffuse pulmonary alveolar hemorrhage after bone marrow transplantation: radiographic findings in 39 patients. AJR Am J Roentgenol 1991; 157: 461-464.

66 Lewis ID, DeFor T, Weisdorf DJ. Increasing incidence of diffuse alveolar hemorrhage following allogeneic bone marrow transplantation: cryptic etiology and uncertain therapy. Bone Marrow Transplant 2000; 26: 539-543.

67 Roychowdhury M, Pambuccian SE, Aslan DL, et al. Pulmonary complications after bone marrow transplantation: an autopsy study from a large transplantation center. Arch Pathol Lab Med 2005; 129: 366-371.

68 Sharma S, Nadrous HF, Peters SG, et al. Pulmonary complications in adult blood and marrow transplant recipients: autopsy findings. Chest 2005; 128: 1385-1392.

69 Rathi NK, Tanner AR, Dinh A, et al. Low-, medium- and high-dose steroids with or without aminocaproic acid in adult hematopoietic SCT patients with diffuse alveolar hemorrhage. Bone Marrow Transplant 2015; 50: 420-426.

70 Afessa B, Tefferi A, Litzow MR, et al. Outcome of diffuse alveolar hemorrhage in hematopoietic stem cell transplant recipients. Am J Respir Crit Care Med 2002; 166: 1364-1368.

71 Pathak V, Kuhn J, Gabriel D, et al. Use of activated factor VII in patients with diffuse alveolar hemorrhage: a 10 years institutional experience. Lung 2015; 193: 375-379.

72 Shimada A, Terada J, Tsushima $\mathrm{K}$, et al. Veno-venous extracorporeal membrane oxygenation bridged living-donor lung transplantation for rapid progressive respiratory failure with pleuroparenchymal fibroelastosis after allogeneic hematopoietic stem cell transplantation. Respir Investig 2018; 56: 258-262.

73 Stretch R, Bonde P. Successful use of extracorporeal membrane oxygenation for respiratory failure in pulmonary chronic graft-versus-host disease. ASAIO J 2014; 60: 122-123.

74 Liao W-I, Tsai S-H, Chiu S-K. Successful use of extracorporeal membrane oxygenation in a hematopoietic stem cell transplant patient with idiopathic pneumonia syndrome. Respir Care 2013; 58: e6-10.

75 Morris SH, Haight AE, Kamat P, et al. Successful use of extracorporeal life support in a hematopoietic stem cell transplant patient with diffuse alveolar hemorrhage. Pediatr Crit Care Med 2010; 11: e4-e7.

76 Wohlfarth P, Beutel G, Lebiedz P, et al. Characteristics and outcome of patients after allogeneic hematopoietic stem cell transplantation treated with extracorporeal membrane oxygenation for acute respiratory distress syndrome. Crit Care Med 2017; 45: e500-e507.

77 Wells AU. Cryptogenic organizing pneumonia. Semin Respir Crit Care Med 2001; 22: 449-460.

78 Nakasone H, Onizuka M, Suzuki N, et al. Pre-transplant risk factors for cryptogenic organizing pneumonia/ bronchiolitis obliterans organizing pneumonia after hematopoietic cell transplantation. Bone Marrow Transplant 2013; 48: 1317-1323.

79 Freudenberger TD, Madtes DK, Curtis JR, et al. Association between acute and chronic graft-versus-host disease and bronchiolitis obliterans organizing pneumonia in recipients of hematopoietic stem cell transplants. Blood 2003; 102: 3822-3828.

80 Soubani AO, Pandya CM. The spectrum of noninfectious pulmonary complications following hematopoietic stem cell transplantation. Hematol Oncol Stem Cell Ther 2010; 3: 143-157.

81 Cordier J-F. Cryptogenic organising pneumonia. Eur Respir J 2006; 28: 422-446.

82 Lee KS, Kullnig P, Hartman TE, et al. Cryptogenic organizing pneumonia: CT findings in 43 patients. AJR Am J Roentgenol 1994; 162: 543-546.

83 Yoshihara S, Yanik G, Cooke KR, et al. Bronchiolitis obliterans syndrome (BOS), bronchiolitis obliterans organizing pneumonia (BOOP), and other late-onset noninfectious pulmonary complications following allogeneic hematopoietic stem cell transplantation. Biol Blood Marrow Transplant 2007; 13: 749-759.

84 Jinta M, Ohashi K, Sakurai C, et al. Cryptogenic organizing pneumonia following allogeneic hematopoietic stem cell transplantation. Blood 2006; 108: 5330-5330.

85 Lazor R, Vandevenne A, Pelletier A, et al. Cryptogenic organizing pneumonia. characteristics of relapses in a series of 48 patients. The groupe d'Etudes et de recherche sur les maladles "orphelines" pulmonaires (GERM"O"P). Am J Respir Crit Care Med 2000; 162: 571-577.

86 Scarlata S, Annibali O, Santangelo S, et al. Pulmonary complications and survival after autologous stem cell transplantation: predictive role of pulmonary function and pneumotoxic medications. Eur Respir J 2017; 49: 1601902.

87 Gyurkocza B, Sandmaier BM. Conditioning regimens for hematopoietic cell transplantation: one size does not fit all. Blood 2014; 124: 344-353.

88 Malik SW, Myers JL, DeRemee RA, et al. Lung toxicity associated with cyclophosphamide use. Two distinct patterns. Am J Respir Crit Care Med 1996; 154: 1851-1856.

89 Helman DL, Byrd JC, Ales NC, et al. Fludarabine-related pulmonary toxicity: a distinct clinical entity in chronic lymphoproliferative syndromes. Chest 2002; 122: 785-790.

90 Pham P-TT, Pham P-CT, Danovitch GM, et al. Sirolimus-associated pulmonary toxicity. Transplantation 2004; 77: $1215-1220$. 
Goligher EC, Cserti-Gazdewich C, Balter M, et al. Acute lung injury during antithymocyte globulin therapy for aplastic anemia. Can Respir J 2009; 16: e3-e5.

92 Soubani AO, Uberti JP. Bronchiolitis obliterans following haematopoietic stem cell transplantation. Eur Respir J 2007; 29: 1007-1019.

93 Kwok WC, Liang BM, Lui MMS, et al. Rapid versus gradual lung function decline in bronchiolitis obliterans syndrome after haematopoietic stem cell transplantation is associated with survival outcome. Respirology 2019; 24: 459-466.

94 Ahn JH, Jo K-W, Song JW, et al. Prognostic role of FEV1 for survival in bronchiolitis obliterans syndrome after allogeneic hematopoietic stem cell transplantation. Clin Transplant 2015; 29: 1133-1139.

95 Amin EN, Phillips GS, Elder P, et al. Health-related quality of life in patients who develop bronchiolitis obliterans syndrome following allo-SCT. Bone Marrow Transplant 2015; 50: 289-295.

96 Ditschkowski M, Elmaagacli AH, Koldehoff M, et al. Bronchiolitis obliterans after allogeneic hematopoietic SCT: further insight--new perspectives? Bone Marrow Transplant 2013; 48: 1224-1229.

97 Gazourian L, Rogers AJ, Ibanga R, et al. Factors associated with bronchiolitis obliterans syndrome and chronic graft-versus-host disease after allogeneic hematopoietic cell transplantation. Am J Hematol 2014; 89: 404-409.

98 Nakasone H, Kanda J, Yano S, et al. A case-control study of bronchiolitis obliterans syndrome following allogeneic hematopoietic stem cell transplantation. Transpl Int 2013; 26: 631-639.

99 Duque-Afonso J, Ihorst G, Wäsch R, et al. Identification of risk factors for bronchiolitis obliterans syndrome after reduced toxicity conditioning before hematopoietic cell transplantation. Bone Marrow Transplant 2013; 48 $1098-1103$.

100 Kuzmina Z, Krenn K, Petkov V, et al. CD19 $\left({ }^{+}\right)$CD21 $\left({ }^{\text {Low }}\right)$ B cells and patients at risk for NIH-defined chronic graft-versus-host disease with bronchiolitis obliterans syndrome. Blood 2013; 121: 1886-1895.

101 Au BKC, Au MA, Chien JW. Bronchiolitis obliterans syndrome epidemiology after allogeneic hematopoietic cell transplantation. Biol Blood Marrow Transplant 2011; 17: 1072-1078.

102 Jagasia MH, Greinix HT, Arora M, et al. National Institutes of Health consensus development project on criteria for clinical trials in chronic graft-versus-host disease: I. The 2014 Diagnosis and Staging Working Group Report. Biol Blood Marrow Transplant 2015; 21: 389-401.e1.

103 Carpenter PA, Kitko CL, Elad S, et al. National Institutes of Health Consensus development project on criteria for clinical trials in chronic graft-versus-host disease: V. The 2014 Ancillary Therapy and Supportive Care Working Group Report. Biol Blood Marrow Transplant 2015; 21: 1167-1187.

104 Williams KM. How I treat bronchiolitis obliterans syndrome after hematopoietic stem cell transplantation. Blood 2017; 129: 448-455.

105 Khalid M, Al Saghir A, Saleemi S, et al. Azithromycin in bronchiolitis obliterans complicating bone marrow transplantation: a preliminary study. Eur Respir J 2005; 25: 490-493.

106 Yates B, Murphy DM, Forrest IA, et al. Azithromycin reverses airflow obstruction in established bronchiolitis obliterans syndrome. Am J Respir Crit Care Med 2005; 172: 772-775.

107 Yadav H, Peters SG, Keogh KA, et al. Azithromycin for the treatment of obliterative bronchiolitis after hematopoietic stem cell transplantation: a systematic review and meta-analysis. Biol Blood Marrow Transplant 2016; 22: 2264-2269.

108 Vos R, Vanaudenaerde BM, Verleden SE, et al. A randomised controlled trial of azithromycin to prevent chronic rejection after lung transplantation. Eur Respir J 2011; 37: 164-172.

109 Or R, Gesundheit B, Resnick I, et al. Sparing effect by montelukast treatment for chronic graft versus host disease: a pilot study. Transplantation 2007; 83: 577-581.

110 Bergeron A, Chevret S, Chagnon K, et al. Budesonide/formoterol for bronchiolitis obliterans after hematopoietic stem cell transplantation. Am J Respir Crit Care Med 2015; 191: 1242-1249.

111 Williams KM, Cheng G-S, Pusic I, et al. FAM treatment for new-onset bronchiolitis obliterans syndrome after hematopoietic cell transplantation. Biol Blood Marrow Transplant 2016; 22: 710-716.

112 Bergeron A, Chevret S, Granata A, et al. Effect of azithromycin on airflow decline-free survival after allogeneic hematopoietic stem cell transplant: the ALLOZITHRO randomized clinical trial. JAMA 2017; 318: 557-566.

113 Cho A, Jantschitsch C, Knobler R. Extracorporeal photopheresis-an overview. Front Med (Lausanne) 2018; 5: 236.

114 Del Fante C, Perotti C. Extracorporeal photopheresis for bronchiolitis obliterans syndrome after allogeneic stem cell transplant: an emerging therapeutic approach? Transfus Apher Sci 2017; 56: 17-19.

115 Watanabe S, Waseda Y, Kimura H, et al. Imatinib for bronchiolitis obliterans after allogeneic hematopoietic stem cell transplantation. Bone Marrow Transplant 2015; 50: 1250-1252.

116 Soubani AO, Kingah P, Alshabani K, et al. Lung transplantation following hematopoietic stem cell transplantation: report of two cases and systematic review of literature. Clin Transplant 2014; $28: 776-782$.

117 Holm AM, Riise GC, Hansson L, et al. Lung transplantation for bronchiolitis obliterans syndrome after allo-SCT. Bone Marrow Transplant 2013; 48: 703-707.

118 Greer M, Berastegui C, Jaksch P, et al. Lung transplantation after allogeneic stem cell transplantation: a pan-European experience. Eur Respir J 2018; 51: 1701330.

119 Tran J, Norder EE, Diaz PT, et al. Pulmonary rehabilitation for bronchiolitis obliterans syndrome after hematopoietic stem cell transplantation. Biol Blood Marrow Transplant 2012; 18: 1250-1254.

120 Khalid M, Aljurf M, Saleemi S, et al. Gastroesophageal reflux disease and its association with bronchiolitis obliterans syndrome in allogeneic hematopoietic stem cell transplant recipients. Exp Clin Transplant 2013; 11: $270-273$.

121 Schlemmer F, Chevret S, Lorillon G, et al. Noninfectious infiltrative lung diseases after allogeneic hematopoietic stem cell transplantation (HSCT). Eur Respir J 2013; 42: Suppl. 57, P2344.

122 Bergeron A, Bengoufa D, Feuillet S, et al. The spectrum of lung involvement in collagen vascular-like diseases following allogeneic hematopoietic stem cell transplantation: report of 6 cases and review of the literature. Medicine (Baltimore) 2011; 90: 146-157.

123 von der Thüsen JH, Hansell DM, Tominaga M, et al. Pleuroparenchymal fibroelastosis in patients with pulmonary disease secondary to bone marrow transplantation. Mod Pathol 2011; 24: 1633-1639.

124 Bondeelle L, Gras J, Michonneau D, et al. Pleuroparenchymal fibroelastosis after allogeneic hematopoietic stem cell transplantation. Bone Marrow Transplant 2019; 55: 982-986. 
Mariani F, Gatti B, Rocca A, et al. Pleuroparenchymal fibroelastosis: the prevalence of secondary forms in hematopoietic stem cell and lung transplantation recipients. Diagn Interv Radiol 2016; 22: 400-406.

Brownback KR, Pitts LR, Abhyankar S. Safety of nintedanib for treatment of fibrotic lung disease after allogeneic hematopoietic stem cell transplantation. Bone Marrow Transplant 2018; 53: 1218-1220.

Takeuchi Y, Miyagawa-Hayashino A, Chen F, et al. Pleuroparenchymal fibroelastosis and non-specific interstitial pneumonia: frequent pulmonary sequelae of haematopoietic stem cell transplantation. Histopathology 2015; 66: 536-544.

Greer M, Riise GC, Hansson L, et al. Dichotomy in pulmonary graft-versus-host disease evident among allogeneic stem-cell transplant recipients undergoing lung transplantation. Eur Respir J 2016; 48: 1807-1810.

Modi D, Jang H, Kim S, et al. Incidence, etiology and outcome of pleural effusions in allogeneic hematopoietic stem cell transplantation. Am J Hematol 2016; 91: E341-E347.

Sakai R, Kanamori H, Nakaseko C, et al. Air-leak syndrome following allo-SCT in adult patients: report from the Kanto study group for cell therapy in Japan. Bone Marrow Transplant 2011; 46: 379-384.

Franquet T, Rodríguez S, Hernández J, et al. Air-leak syndromes in hematopoietic stem cell transplant recipients with chronic GVHD: high-resolution CT findings. J Thorac Imaging 2007; 22: 335-340.

Moon MH, Sa YJ, Cho KD, et al. Thoracic air-leak syndromes in hematopoietic stem cell transplant recipients with graft-versus-host disease: a possible sign for poor response to treatment and poor prognosis. J Korean Med Sci 2010; 25: 658-662.

Peña E, Souza CA, Escuissato DL, et al. Noninfectious pulmonary complications after hematopoietic stem cell transplantation: practical approach to imaging diagnosis. RadioGraphics 2014; 34: 663-683.

Zahid M, Murad M, Litzow M, et al. Venous thromboembolism following hematopoietic stem cell transplantation-a systematic review and meta-analysis. Ann Hematol 2016; 95: 1457-1464.

Gerber DE, Segal J, Levy MY, et al. the incidence of and risk factors for venous thromboembolism (VTE) and bleeding among 1514 patients undergoing hematopoietic stem cell transplantation: implications for VTE prevention. Blood 2008; 112: 504-510.

O'Hara VJ, Miller T, Mehta R, et al. Incidence of venous thromboembolism in the setting of hematopoietic cell transplantation. Am J Ther 2014; 21: 15-19.

Paul TM, Liu SV, Chong EA, et al. Outpatient autologous stem cell transplantation for patients with myeloma. clinical lymphoma. Myeloma Leukemia 2015; 15: 536-540.

Labrador J, Lopez-Anglada L, Perez-Lopez E, et al. Analysis of incidence, risk factors and clinical outcome of thromboembolic and bleeding events in 431 allogeneic hematopoietic stem cell transplantation recipients. Haematologica 2013; 98: 437-443.

Kekre N, Connors JM. Venous thromboembolism incidence in hematologic malignancies. Blood Rev 2019; 33: 24-32.

Kekre N, Kim HT, Ho VT, et al. Venous thromboembolism is associated with graft-versus-host disease and increased non-relapse mortality after allogeneic hematopoietic stem cell transplantation. Haematologica 2017; 102: 1185-1191.

Kaufman PA, Jones RB, Greenberg CS, et al. Autologous bone marrow transplantation and factor xii, factor vi and protein $c$ deficiencies report of a new association and its possible relationship to endothelial cell injury. Cancer 1990; 66: 515-521.

Fujimori Y, Takatsuka H, Takemoto Y, et al. Elevated interleukin (IL)-18 levels during acute graft-versus-host disease after allogeneic bone marrow transplantation. Br J Haematol 2000; 109: 652-657.

Palomo M, Diaz-Ricart M, Carbo C, et al. Endothelial dysfunction after hematopoietic stem cell transplantation: role of the conditioning regimen and the type of transplantation. Biol Blood Marrow Transplant 2010; 16: 985-993. Biedermann BC, Sahner S, Gregor M, et al. Endothelial injury mediated by cytotoxic T lymphocytes and loss of microvessels in chronic graft versus host disease. Lancet 2002; 359: 2078-2083.

Zeidan AM, Wellman J, Forde PM, et al. Venous thromboembolism prophylaxis in hematopoietic stem cell transplantation patients: an international web-based survey of healthcare providers. J Thromb Thrombolysis 2014; 37: 524-526.

6 Labrador J, González-Rivero J, Monroy R, et al. Management patterns and outcomes in symptomatic venous thromboembolism following allogeneic hematopoietic stem cell transplantation. a 15-years experience at a single center. Thromb Res 2016; 142: 52-56.

Simonneau G, Montani D, Celermajer DS, et al. Haemodynamic definitions and updated clinical classification of pulmonary hypertension. Eur Respir J 2018: 53: 1801913.

Dandoy CE, Hirsch R, Chima R, et al. Pulmonary hypertension after hematopoietic stem cell transplantation. Biol Blood Marrow Transplant 2013; 19: 1546-1556.

Bunte MC, Patnaik MM, Pritzker MR, et al. Pulmonary veno-occlusive disease following hematopoietic stem cell transplantation: a rare model of endothelial dysfunction. Bone Marrow Transplant 2008; 41: 677-686.

Nathan SD, Shlobin OA, Ahmad S, et al. Pulmonary hypertension in patients with bronchiolitis obliterans syndrome listed for retransplantation. Am J Transplant 2008; 8: 1506-1511.

Pate A, Rotz S, Warren M, et al. Pulmonary hypertension associated with bronchiolitis obliterans after hematopoietic stem cell transplantation. Bone Marrow Transplant 2016; 51: 310-312.

Halkos ME, Miller JI, Mann KP, et al. Thoracic presentations of posttransplant lymphoproliferative disorders. Chest 2004; 126: 2013-2020.

Salh OS, Nadhem ON, Thakore SR, et al. A 47-year-old stem cell transplant recipient with fever, cough and chest pain. Can Respir J 2015; 22: 144-146.

Oncol 2018; 19: 9

Heslop HE, Slobod KS, Pule MA, et al. Long-term outcome of EBV-specific T-cell infusions to prevent or treat EBV-related lymphoproliferative disease in transplant recipients. Blood 2010; 115: 925-935. hematopoietic cell transplantation. Blood 2009; 113: 4992-5001.

Curtis RE, Metayer C, Rizzo JD, et al. Impact of chronic GVHD therapy on the development of squamous-cell cancers after hematopoietic stem-cell transplantation: an international case-control study. Blood 2005; 105: 3802-3811. 
Styczynski J, van der Velden W, Fox CP, et al. Management of Epstein-Barr virus infections and post-transplant lymphoproliferative disorders in patients after allogeneic hematopoietic stem cell transplantation: Sixth European Conference on Infections in Leukemia (ECIL-6) Guidelines. Haematologica 2016; 101: 803-811.

159 Yoon GY, Kim MY, Huh JR, et al. Posttransplant lymphoproliferative disorder of the thorax: CT and FDG-PET features in a single tertiary referral center. Medicine (Baltimore) 2015; 94.

160 Loren AW, Tsai DE. Post-transplant lymphoproliferative disorder. Clin Chest Med 2005; 26: 631-645.

161 Siegel MJ, Lee EY, Sweet SC, et al. CT of Post-transplantation lymphoproliferative disorder in pediatric recipients of lung allograft. AJR Am J Roentgenol 2003; 181: 1125-1131.

162 Copp DH, Godwin JD, Kirby KA, et al. Clinical and radiologic factors associated with pulmonary nodule etiology in organ transplant recipients. Am J Transplant 2006; 6: 2759-2764.

163 Kunitomi A, Arima N, Ishikawa T. Epstein-Barr virus-associated post-transplant lymphoproliferative disorders presented as interstitial pneumonia; successful recovery with rituximab. Haematologica 2007; 92: e49-e52.

164 Xu L-P, Huang X-J, Liu D-H, et al. [A clinical study of lymphoproliferative disorders following allogeneic hematopoietic stem cell transplantation]. Zhonghua Nei Ke Za Zhi 2007; 46: 996-999.

165 Liu Q-F, Fan Z-P, Luo X-D, et al. Epstein-Barr virus-associated pneumonia in patients with post-transplant lymphoproliferative disease after hematopoietic stem cell transplantation. Transpl Infect Dis 2010; 12: 284-291.

166 Fox CP, Burns D, Parker AN, et al. EBV-associated post-transplant lymphoproliferative disorder following in vivo T-Cell-depleted allogeneic transplantation: clinical features, viral load correlates and prognostic factors in the rituximab era. Bone Marrow Transplant 2014; 49: 280-286.

167 Ahmad I, Cau NV, Kwan J, et al. Pre-emptive management of Epstein-Barr virus reactivation after hematopoietic stem-cell transplantation. Transplantation 2009; 87: 1240-1245.

168 Styczynski J, Gil L, Tridello G, et al. Response to rituximab-based therapy and risk factor analysis in EpsteinBarr virus-related lymphoproliferative disorder after hematopoietic stem cell transplant in children and adults: a study from the Infectious Diseases Working Party of the European Group for Blood and Marrow Transplantation. Clin Infect Dis 2013; 57: 794-802.

169 van der Velden WJFM, Mori T, Stevens WBC, et al. Reduced PTLD-related mortality in patients experiencing EBV infection following allo-SCT after the introduction of a protocol incorporating pre-emptive rituximab. Bone Marrow Transplant 2013; 48: 1465-1471.

170 Worth A, Conyers R, Cohen J, et al. Pre-emptive rituximab based on viraemia and T cell reconstitution: a highly effective strategy for the prevention of Epstein-Barr virus-associated lymphoproliferative disease following stem cell transplantation. Br J Haematol 2011; 155: 377-385.

171 Xuan L, Jiang X, Sun J, et al. Spectrum of Epstein-Barr virus-associated diseases in recipients of allogeneic hematopoietic stem cell transplantation. Transplantation 2013; 96: 560-566.

172 Caillot D, Casasnovas O, Bernard A, et al. Improved management of invasive pulmonary aspergillosis in neutropenic patients using early thoracic computed tomographic scan and surgery. J Clin Oncol 1997; 15: 139-147.

173 Chellapandian D, Lehrnbecher T, Phillips B, et al. Bronchoalveolar lavage and lung biopsy in patients with cancer and hematopoietic stem-cell transplantation recipients: a systematic review and meta-analysis. J Clin Oncol 2015; 33: 501-509.

174 Bauer PR, Chevret S, Yadav H, et al. Diagnosis and outcome of acute respiratory failure in immunocompromised patients after bronchoscopy. Eur Respir J 2019; 54: 1802442.

175 Legoff J, Zucman N, Lemiale V, et al. Clinical significance of upper airway virus detection in critically ill hematology patients. Am J Respir Crit Care Med 2019; 199: 518-528.

176 Cheng GS, Stednick ZJ, Madtes DK, et al. Decline in the use of surgical biopsy for diagnosis of pulmonary disease in hematopoietic cell transplantation recipients in an era of improved diagnostics and empirical therapy. Biol Blood Marrow Transplant 2016; 22: 2243-2249.

177 Hildebrandt GC, Fazekas T, Lawitschka A, et al. Diagnosis and treatment of pulmonary chronic GVHD: report from the consensus conference on clinical practice in chronic GVHD. Bone Marrow Transplant 2011; 46: $1283-1295$.

178 Verleden GM, Glanville AR, Lease ED, et al. Chronic lung allograft dysfunction: Definition, diagnostic criteria and approaches to treatment-a consensus report from the Pulmonary Council of the ISHLT. J Heart Lung Transplant 2019; 38: 493-503. 